\title{
Comparison of minimally invasive surfactant therapy with intubation surfactant administration and extubation for treating preterm infants with respiratory distress syndrome: a randomized clinical trial
}

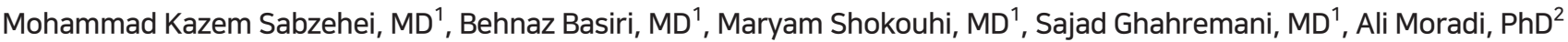 \\ ${ }^{1}$ Department of Pediatrics, Hamadan University of Medical Sciences, Hamadan, Iran; ${ }^{2}$ Health Deputy, Hamadan University of Medical Sciences, Hamadan, Iran
}

Background: Respiratory distress syndrome (RDS) is a common cause of hospitalization and death in preterm infants who require surfactant treatment and respiratory support.

Purpose: This study aimed to compare the clinical outcomes of minimally invasive surfactant therapy (MIST) and the INtubation, SURfactant administration, and Extubation (INSURE) technique in preterm infants with RDS.

Methods: In this clinical trial, 112 preterm infants born at 28-36 weeks of gestation and diagnosed with RDS randomly received $200-\mathrm{mg} / \mathrm{kg}$ surfactant by MIST or the INSURE method. In the MIST group, surfactant was administered using a thin catheter (5F feeding tube); in the INSURE group, surfactant was administered after intubation using a feeding tube and the tracheal tube was removed after positive pressure ventilation was started. Nasal continuous positive airway pressure was applied in both groups for respiratory support and the postprocedure clinical outcomes were compared.

Results: The mean hospitalization time was shorter for infants in the MIST group than for those in the INSURE group $(9.19 \pm$ 1.72 days vs. $10.21 \pm 2.15$ days, $P=0.006$ ). Patent ductus arteriosus was less frequent in the MIST group (14.3\% vs. $30.4 \%$, $P=0.041)$. Desaturation during surfactant administration occurred less commonly in the MIST group (19.6\% vs. $39.3 \%$, $P=0.023)$. There were no significant intergroup differences in other early or late complications.

Conclusion: These results suggest that surfactant administration using MIST could be a good replacement for INSURE in preterm infants with RDS since its use reduced the hospitalization time and the number of side effects.

Key words: Respiratory distress syndrome, Preterm infant, Insure, Minimally invasive surfactant therapy

\begin{abstract}
Key message
Question: Are the short-term outcomes of minimally invasive surfactant therapy (MIST) relatively superior to those of INtubation, SURfactant administration, and Extubation (INSURE) in preterm infants with respiratory distress syndrome (RDS)?

Finding: MIST could be an appropriate substitution for INSURE in preterm infants with RDS since it reduced hospitalization time and number of side effects.

Meaning: MIST is recommended for surfactant administration for its proven advantages over the INSURE technique.
\end{abstract}

\section{Introduction}

Respiratory distress syndrome (RDS) usually affects preterm infants and has an inverse relation with gestational age and birth weight. It has been reported in 60\%-80\% cases born at less than 28 weeks of gestational age and in 10\%-15\% cases born at $32-$ 36 weeks of gestational age. ${ }^{1)}$ Currently, the preferred strategy to treat RDS is early nasal continuous positive airway pressure (NCPAP) and a selective use of surfactant for babies with increasing need for oxygen, in which case surfactant administration can reduce the need of oxygen therapy, mechanical ventilation, air-leak syndrome, and mortality. ${ }^{2)}$ Surfactant administration is carried out in 2 methods. In INtubation, SURfactant administration, and Extubation (INSURE), which is the most common method, the baby is first intubated and then extubated after surfactant administration. ${ }^{3)}$ However, sometimes tracheal intubation fails and causes hypoxia, bradycardia, increased intracranial pressure, and respiratory system injury. ${ }^{4)}$ Moreover, mechanical ventilation can cause barotrauma and lung injuries making the infant susceptible to chronic lung disease. ${ }^{5)}$

In minimally invasive surfactant therapy (MIST), surfactant is injected into trachea using a thin catheter with using forceps in direct laryngoscopy. ${ }^{6,7)}$ Using the new and less invasive strategy of MIST in surfactant administration is increasingly growing

Corresponding author: Maryam Shokouhi, MD, Department of Pediatrics, Hamadan University of Medical Sciences, Hamadan, Iran, 凶mail: shokohisolgi@umsha.ac.ir, https://orcid.org/0000-0002-5008-7779

Received: 17 March, 2021, Revised: 4 July, 2021, Accepted: 7 July, 2021

This is an open-access article distributed under the terms of the Creative Commons Attribution Non-Commercial License (http://creativecommons.org/licenses/bync/4.0/) which permits unrestricted non-commercial use, distribution, and reproduction in any medium, provided the original work is properly cited.

Copyright (c) 2022 by The Korean Pediatric Society 


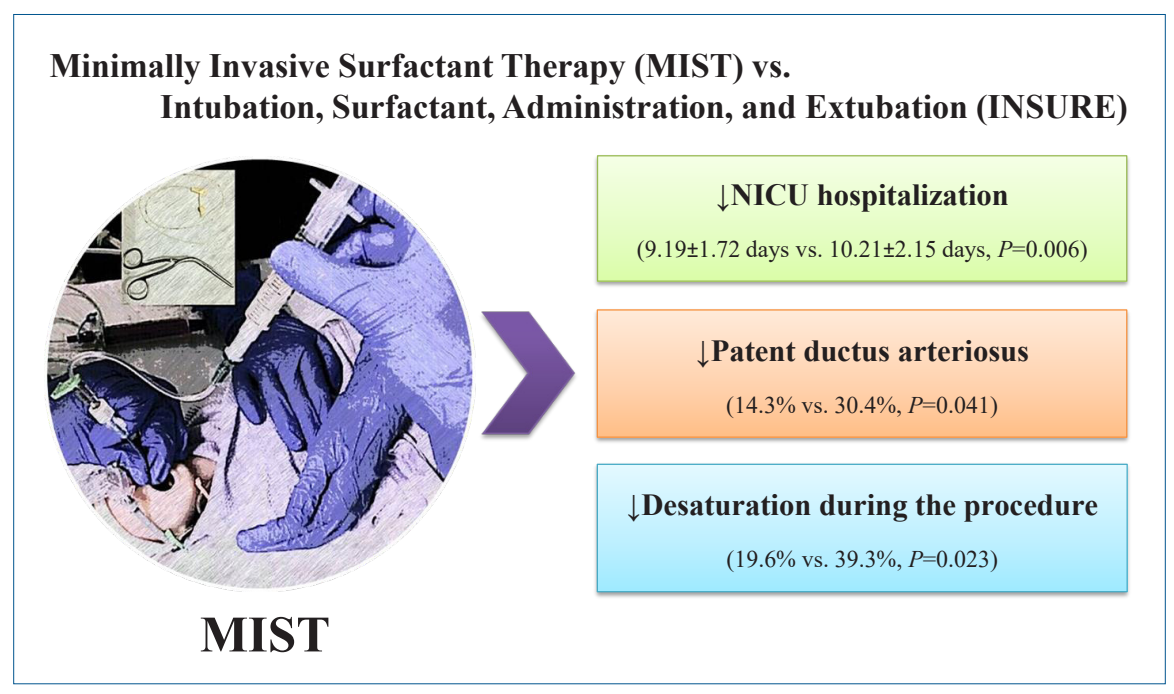

Graphic abstract

and studies, carried out mostly in developed countries, ${ }^{8,9)}$ have shown the advantages and feasibility of MIST in treating premature infants with RDS. ${ }^{10)}$

Given that recent studies have shown that MIST could result in higher recovery rate without bronchopulmonary dysplasia (BPD) and reduce other complications associated with premature birth such as severe intraventricular hemorrhage (IVH). ${ }^{11,12)}$

The objectives of this study were to evaluate the effectiveness and short-term outcomes of MIST and compare them with the INSURE technique in the treatment of RDS in preterm infants born between 28-36 weeks of gestational age.

\section{Methods}

\section{Study population}

This study was a clinical trial including 112 preterm infants with RDS hospitalized in neonatal intensive care unit (NICU) at Fatemieh Hospital affiliated to Hamadan University of Medical Sciences in 2019-2020. All preterm infants born at 28 to 36 weeks of gestational age and diagnosed with RDS by pediatrician or neonatologist based on clinical symptoms, chest imaging, and arterial blood gas analysis were included in the study, and those with multiple congenital anomalies, need for intubation in the delivery room and a 5 -minute Apgar score $\leq 4$ were excluded. ${ }^{13}$ )

\section{Randomization and masking}

1) Randomization

Upon completing the baseline evaluation, patients were randomized to either intervention or control groups. Randomization was performed using a permuted block randomization method (with block sizes of 4 or 6 and allocation ratio of 1:1). Block randomization is used to reduce bias and achieve balance in the allocation of participants to treatment arms. The random allocation sequence was computer-generated (Kendall and Smith's Random Numbers Table) by a statistician who was not a part of the research team. The random allocation sequence was concealed in sealed opaque envelops until the participants were assigned into 2 groups.

\section{2) Blinding}

In the first stage, the researcher uses the inclusion and exclusion criteria of the study to prepare a list of eligible infants to participate in this study. The research assistant contacts all eligible parents to register. If they wish and consent to participate in this research study, general information and written consent will be obtained from the parents and then baseline assessment will be performed. In this research, the evaluator is blinded. Then, 112 infants with respiratory distress are randomly divided into 2 groups using block randomization method by hiding random allocation allocation (Fig 1). Random sequencing is done using random numbers generated by a computer. The data collector and statistical analyzer were also not informed about the allocation of patients to study groups.

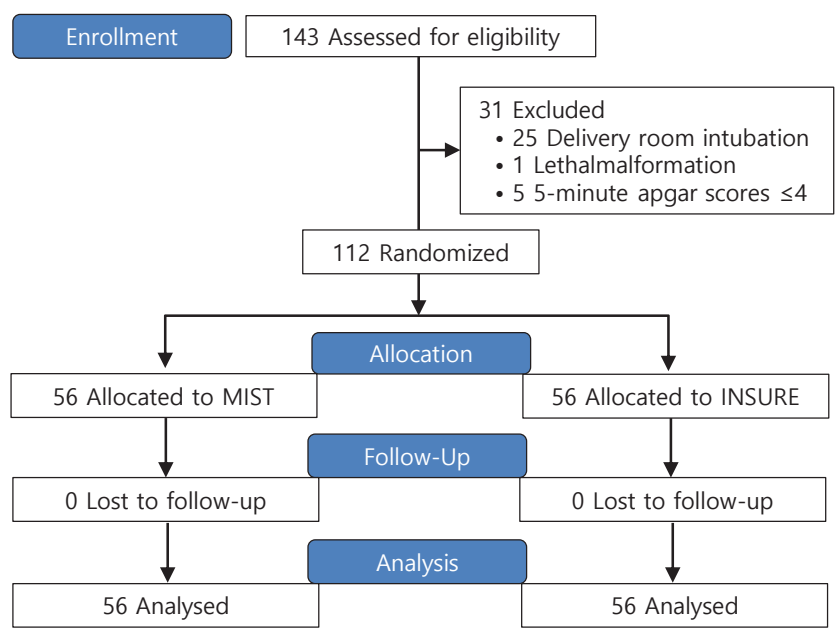

Fig. 1. Participant study enrollment and group allocation process. INSURE, INtubation, SURfactant, and Extubation; MIST, minimal invasive surfactant treatment. 
3) Sample selection

The following formula was used to determine the sample size needed for selecting the intervention and control groups considering 0.01 error level and 95\% confidence level. The mean value difference (standard deviation) of NICU hospitalization time was extracted from Mosayebi et al. ${ }^{13)}$ and was considered 3.2 (1.7).

In each group, 56 infants were selected by random sampling.

$$
\begin{aligned}
& n=\frac{\left(Z_{1-\frac{a}{2}}+Z_{1-\beta}\right) \times\left[\delta_{1}^{2}+\delta_{1}^{2}\right]^{2}}{\left(\mu_{1}-\mu_{2}\right)^{2}} \\
& n=\frac{(2.57+1.96) \times(10.4+7.2)^{2}}{(9-7.3)^{2}}=56
\end{aligned}
$$

4) Intervention

All preterm infants born in the delivery room or operating room who had spontaneous breathing but had respiratory distress at the time of birth were applied NCPAP to stabilize their breathing condition, starting with T-piece resuscitator (Neopuff Fisher \& Paykel Healthcare, Auckland, New Zealand) at positive end expiratory pressure levels of $5-6 \mathrm{cmH}_{2} \mathrm{O}$ and continue during transfer to NICU. Nasal prong was used and an orogastric tube was inserted to prevent abdominal distension and cardiopulmonary monitoring was also performed.

Continuous positive airway pressure (CPAP) level varied from 5 to $8 \mathrm{cmH}_{2} \mathrm{O}$ and $\mathrm{FiO}_{2}$ was adjusted to preserve 90\%-95\% oxygen saturation. Next, if the infants needed $\mathrm{FiO}_{2}>40 \%$ to preserve arterial oxygen saturation, they received surfactant with MIST or INSURE. The infants were divided randomly into the study (MIST) group and control (INSURE) group and then received surfactant by each method.

In control group, the infants went under tracheal intubation using a proper diameter based on the weight and gestational age. Then, 200-mg/kg Curosurf (Curosurf, Chiesi Farmaceutici group, Parma, Italy) surfactant was administered through tracheal tube using a feeding tube in 1-3 minutes. After that, the infants received positive pressure ventilation and were extubated and NCPAP was set up. If $\mathrm{FiO}_{2}>40 \%$ was needed to preserve $90 \%-95 \%$ arterial oxygen saturation after 6-12 hours, second dose of surfactant was administered.

In study group, a $5 \mathrm{~F}$ feeding tube was used to pass through vocal cords slowly with direct laryngoscopy. If it was not possible to pass the feeding tube after 30 seconds, NCPAP was setup and catheter passage was attempted again. The dosage and method of surfactant administration were the same as control group. Oxygen saturation and heart rate were monitored during surfactant administration. If oxygen saturation level was lower than $80 \%$ or if heart rate dropped lower than 100 beat per minute, the procedure was stopped and the infant was oxygenated. After the procedure, gastric suction was performed to ascertain intratracheal surfactant administration. Finally, the feeding tube was removed, NCPAP was applied, and $\mathrm{FiO}_{2}$ level was lowered gradually. ${ }^{13)}$

Intravenous caffeine was injected to all infants in both groups with $20-\mathrm{mg} / \mathrm{kg}$ initial dose and $5 \mathrm{mg} / \mathrm{kg}$ daily dose. Moreover, the infants were intubated and mechanical ventilation was performed in case of respiratory acidosis $\left(\mathrm{pH}<7.2\right.$ with $\mathrm{PCO}_{2}>60$ $65 \mathrm{mmHg})$, hypoxia $\left(\mathrm{PaO}_{2}<50 \mathrm{mmHg}\right.$ despite receiving oxygen or $\mathrm{FiO}_{2}>40 \%$ under NCPAP), and severe apnea.

INSURE and MIST procedures were carried out by neonatology fellows.

\section{5) Outcomes}

The primary outcome was the need for intubation in the first 72 hours of life. The secondary outcomes were incidence of IVH grade $\geq 2$, BPD (oxygen dependence at 36 weeks gestational age), patent ductus arteriosus (PDA), pulmonary hemorrhage, necrotizing enterocolitis (NEC) stage $\geq$ II, retinopathy of prematurity (ROP) stage $>2$ and duration of hospitalization. ${ }^{13,14)}$

\section{Statistical analysis}

Descriptive statistics was used with mean and standard deviation expression for quantitative variables and ratio and percentage qualitative variables. Student $t$ test and chi-square test were used for quantitative and qualitative variables, respectively. IBM SPSS Statistics ver. 20.0 (IBM Co., Armonk, NY, USA) was used for data analysis in this study. Statistical significance level was considered less than 0.05 .

\section{Ethical considerations}

The study protocol was reviewed and approved by the Ethics Committees of Hamadan University of Medical Sciences, Hamadan, Iran (number: IR.UMSHA.REC.1398.457). This study was registered at the Iranian Registry for Clinical Trials (code: IRCT20160523028008N81). The completed questionnaires and collected data were confidential.

Table 1. Comparison of demographical and clinical information of both groups

\begin{tabular}{lccc}
\hline Variable & INSURE $(\mathrm{n}=56)$ & MIST $(\mathrm{n}=56)$ & $P$ value \\
\hline Gestational age (wk) & $30.58 \pm 3.40$ & $29.65 \pm 3.02$ & 0.127 \\
Gestational age group (wk) & & & 0.291 \\
$28-32$ & $38(67.9)$ & $43(76.8)$ & \\
$33-36$ & $18(32.1)$ & $13(23.2)$ & \\
Birth weight (g) & $1,677.91 \pm 542.79$ & $1,530.21 \pm 506.77$ & 0.139 \\
Male sex & $38(67.9)$ & $37(66.1)$ & 0.841 \\
Maternal age (yr) & $26.62 \pm 3.35$ & $26.98 \pm 4.14$ & 0.617 \\
Apgar score at 1 min & $6.05 \pm 0.81$ & $5.87 \pm 0.91$ & 0.279 \\
Apgar score at 5 min & $7.96 \pm 0.97$ & $7.75 \pm 0.83$ & 0.213 \\
Twin & $13(23.2)$ & $14(25.0)$ & 0.825 \\
Cesarean section & $44(78.6)$ & $41(73.2)$ & 0.508 \\
Antenatal steriod & $38(67.9)$ & $33(55.9)$ & 0.327 \\
Maternal disease & & & 0.254 \\
Gestational diabetes & $6(10.7)$ & $7(12.5)$ & \\
Preeclampsia & $7(12.5)$ & $15(26.8)$ & \\
Chorioamniotitis & $7(12.5)$ & $5(8.9)$ & \\
\hline
\end{tabular}

Values are presented as mean \pm standard deviation or number (\%). INSURE, INtubation, SURfactant administration, and Extubation; MIST, minimal invasive surfactant treatment. 
Table 2. Comparison of primary outcomes in both groups

\begin{tabular}{lccc}
\hline Variable & INSURE $(\mathrm{n}=56)$ & MIST (n=56) & $P$ value \\
\hline Surfactant administration 1st dose (hr) & $3.03 \pm 1.70$ & $2.68 \pm 1.49$ & $0.252^{\mathrm{a})}$ \\
Surfactant Administration 2nd dose (hr) & $10(17.9)$ & $6(10.7)$ & 0.280 \\
Duration of oxygen requirement (hr) & $85.87 \pm 16.14$ & $85.44 \pm 14.83$ & $0.884^{\mathrm{a})}$ \\
Duration of CPAP (day) & $7.82 \pm 1.55$ & $8.14 \pm 1.63$ & 0.287 \\
Intubation in the first 72 hours & $21(37.5)$ & $18(32.1)$ & 0.552 \\
Need for mechanical ventilation & $15(26.8)$ & $12(21.4)$ & 0.508 \\
Duration of mechanical ventilation (day) & $11.37 \pm 1.96$ & $12.16 \pm 3.43$ & 0.140 \\
Surfactant reflux & $13(23.2)$ & $9(16.1)$ & 0.341 \\
Coughing & $31(55.4)$ & $28(44.6)$ & 0.257 \\
Bradycardia & $13(23.2)$ & $7(12.5)$ & 0.139 \\
Desaturation & $22(39.2)$ & $11(19.6)$ & 0.023 \\
Apnea & $10(17.9)$ & $11(19.6)$ & 0.809 \\
Pneumothorax & $3(5.4)$ & $2(3.6)$ & 0.647 \\
\hline
\end{tabular}

Values are presented as mean \pm standard deviation or number (\%).

INSURE, INtubation, SURfactant administration, and Extubation; MIST, minimal invasive surfactant treatment; CPAP, continuous positive airway pressure. Boldface indicates a statistically significant difference with $P<0.05$.

${ }^{a)} t$ test.

\section{Results}

In this study, 112 preterm infants born at 28 to 36 weeks of gestational age and diagnosed with RDS who met the inclusion criteria were randomly divided into intervention and control groups.

The mean gestational age and birth weight were not significantly different between MIST and INSURE groups (29.65 \pm 3.02 weeks vs. $30.58 \pm 3.40$ weeks, $P=0.127$ and $1530.21 \pm 506.77 \mathrm{~g}$ vs. $1677.91 \pm 542.79 \mathrm{~g}, P=0.139$, respectively). No difference was observed in the clinical characteristics of infants in randomization stage and thus the groups were comparable (Table 1).

The success rate of catheter insertion on the first attempt was $68 \%$ in the MIST group, and therefore the procedure had to be repeated in 18 of the infants.

In the comparison of outcomes, desaturation during the procedure was significantly lower in the MIST group than in the INSURE group $(P=0.023)$. The mean times of the initial surfactant administration in the MIST and INSURE groups were $2.68 \pm 1.49$ hours vs $3.03 \pm 1.70$ hours, $P=0.252$, respectively. Second dose of surfactant, intubation in the first 72 hours, need for mechanical ventilation, bradycardia, coughing, and pneumothorax were lower in MIST group, but there was no statistical significance compared with INSURE group. Respiratory support including duration of CPAP and duration of mechanical ventilation were not significantly different between the 2 groups (Table 2).

In comparing secondary outcome and NICU hospitalization time, it was observed that PDA was 2 times more than MIST group in INSURE group $(P=0.041)$ and NICU hospitalization time was less in MIST group with a significant difference $(P=0.006)$. Other complications were not significantly different between the 2 groups (Table 3 ).
Table 3. Comparison of secondary outcomes in both groups

\begin{tabular}{lccc}
\hline Variable & INSURE $(\mathrm{n}=56)$ & MIST $(\mathrm{n}=56)$ & $P$ value \\
\hline Intraventricular hemorrhage & $3(5.4)$ & $2(3.6)$ & 0.647 \\
Pulmonary hemorrhage & $2(3.6)$ & $1(1.8)$ & 0.558 \\
Bronchopulmonary dysplasia & $6(10.7)$ & $4(7.1)$ & 0.508 \\
Patent ductus arteriosus & $17(30.4)$ & $8(14.3)$ & 0.041 \\
Retinopathy of prematurity & $1(1.8)$ & $2(3.6)$ & 0.558 \\
Necrotizing enterocolitis & $3(5.4)$ & $2(3.6)$ & 0.647 \\
Hospitalization time (day) & $10.21 \pm 2.15$ & $9.19 \pm 1.72$ & 0.006 \\
\hline
\end{tabular}

Values are presented as number (\%) or mean \pm standard deviation.

INSURE, INtubation, SURfactant administration, and Extubation; MIST, minimal invasive surfactant treatment.

Boldface indicates a statistically significant difference with $P<0.05$.

\section{Discussion}

In recent years, surfactant administration by a less invasive method has been introduced as a replacement for standard intubation in preterm infants with RDS. Nonetheless, more comprehensive studies are needed to change the view and determine its effect on neonatal outcome. This study showed that surfactant administration by MIST in preterm infants with RDS could be a good replacement for INSURE method as it reduced NICU hospitalization time and had less complications such as desaturation during surfactant administration and PDA.

In this study, the first attempt success rate of catheter insertion was 68\% in MIST group. Mosayebi et al., ${ }^{13)}$ Dargaville et al., ${ }^{15}$ ) and de Kort et al. ${ }^{16)}$ reported 75\%, 80\%, and 52\% first attempt success, respectively. Lack of experience and nonuse of sedative drugs before the procedure increase the failure rate for catheter insertion in the MIST group. Nonetheless, the side-effects of MIST without premedication have to be accurately assessed compared with the negative effects and dangers of sedative administration. ${ }^{16)}$ 
Coughing was the most common complication and almost half of the patients were affected because intubation was performed without sedative. Other studies have reported the frequency of coughing $11 \%$ to $32 \%,{ }^{17)}$ however, it was reported $12 \%$ in MIST group but it was not reported in infants with post-sedative intubation.

In this study, surfactant reflux was observed in $23.2 \%$ and $16.1 \%$ of babies in INSURE and MIST groups, respectively. Surfactant reflux in MIST was less than in Mosayebi et al. ${ }^{13)}$ and Dargaville et al. ${ }^{15)}$ that reported $22.2 \%$ and $33.3 \%$, respectively. However, their findings on reflux in INSURE were similar to the results of this study.

In this study, $12.5 \%$ of infants in MIST group were affected by bradycardia versus $23.5 \%$ in INSURE group. Different studies have reported it between $17 \%$ to $44 \% .^{13,15,18)}$

In a study by Kribs et al., ${ }^{19)}$ atropine was administrated before intubation and bradycardia was 7.4\%. This self-limiting complication happens because of stimulations during the attempt to see the vocal cords and is mostly resolved after a few-minute pause. ${ }^{15)}$

Desaturation $\left(\mathrm{SaO}_{2}\right.$ drop) during administration was less in MIST group with a statistically significant difference which was congruent with the study by Mirnia et al. ${ }^{20)}$ This could be because there is no need for sedative in MIST patients.

In this study, 200-mg/kg surfactant was administered in both groups as the first dose and approximately $18 \%$ in INSURE group and $11 \%$ in MIST group needed the second dose. In the study by Kanmaz et al., ${ }^{18)}$ the first dose was $100 \mathrm{mg} / \mathrm{kg}$ and almost $20 \%$ of patients needed the second dose in both groups. In the study by Aguar et al.,21) patients received 100- and 200-mg surfactant in MIST and INSURE groups, respectively. Moreover, the results showed that approximately 36\% in MIST group and only 6.5\% in INSURE group needed the second dose of surfactant. In the studies by Niemarkt et al. ${ }^{22}$ and De Luca et al., ${ }^{23)}$ the first dose of administered surfactant was higher in MIST group and there was no need for second dose. In the study by Janssen et al., ${ }^{24)}$ lower than $200-\mathrm{mg} / \mathrm{kg}$ surfactant dose resulted in MIST failure. It appears that higher first dose and the need for second dose are related to clinical knowledge on surfactant leakage, surfactant loss in the equipment, and the different lung distribution of surfactant.

In this study, $32.1 \%$ of MIST group and $37.5 \%$ of INSURE group needed intubation in the first 72 hours after surfactant administration. This was congruent with the study by Mosayebi et al. ${ }^{13)}$ with 30\% in MIST and 25\% in INSURE as well as other studies. ${ }^{2526)}$ However, Dargaville et al. ${ }^{15)}$ showed that although intubation was less needed in MIST group for infants at 25 to 28 weeks of gestational age, there was no significant difference in infants at 29 to 32 weeks of gestational age.

There was no difference in terms of the frequency and duration of mechanical ventilation between the 2 groups. Nonetheless, Tomar et al. ${ }^{25}$ ) reported less mechanical ventilation time for preterm infants born at 34 weeks' gestational age or less in MIST group. Aldana-Aguirre et al. ${ }^{11)}$ and Bugter et al. ${ }^{27)}$ confirmed less need for mechanical ventilation in MIST.

The results of this study showed that PDA was less in the infants in MIST group with a statistically significant difference (14.3\% vs. $30.4 \%)$. This was congruent with Wang et al. ${ }^{28)}$ Other studies have reported approximately $13 \%$ to $36 \%$ and $7 \%$ to $63 \%$ PDA in MIST and INSURE groups, respectively. ${ }^{15,21)}$ It has been shown that the minimally invasive surfactant administration method lowers the risk of PDA and its surgical treatment. ${ }^{29)}$

BPD was seen in 10.7\% of infants in INSURE group and 7.1\% of infants in MIST group in this study, which was more than Mosayebi et al. ${ }^{13)}$ and Dargaville et al. ${ }^{15)}$ with 3.8\% and 3.6\%, respectively. BPD is between $10 \%$ to $20 \%$ in infants at 28 weeks' gestational age or less. ${ }^{15)}$ Higher BPD in INSURE could be because of the damage caused by intubation and short ventilation with positive pressure during surfactant administration. On the other hand, it is believed that spontaneous breathing in MIST distributes surfactant uniformly with less damage, decreasing the occurrence of BPD. . $^{13,30)}$

There was no significant difference between the 2 groups in terms of other complications such as pneumothorax, pulmonary hemorrhage, IVH grade II, NEC, and ROP. This was congruent with the results found in the studies by Mosayebi et al. ${ }^{13)}$ and Kanmaz et al. ${ }^{18)}$

According to the findings in this study, NICU hospitalization time was less in MIST group with a significant difference. This was congruent with the reduced average days of hospitalization in infants who received MIST in the study by Kribs et al. ${ }^{19)} \mathrm{Hos}$ pitalization time was less in MIST group in the study by Mosayebi et al. ${ }^{13)}$ although there was no statistically significant difference. However, NICU hospitalization time was more in MIST group in the study by Aguar et al., ${ }^{21)}$ although it was not statistically significant. In addition to the clinical condition of the patient, several factors could affect NICU hospitalization time such as physician's opinion and hospital facilities.

Limitation to one medical center, inclusion of babies with above 28 weeks' gestational age, and using Curosurf surfactant could limit the generalizability of the results. It seems necessary to carry out additional multicenter trials including extremely preterm infants.

The strong points in this study were accurate observance of protocols in NICU, which reduces the variety of care among specialists and nurses. Moreover, accurate file recording and complete and reliable data were among the other strong points in this study.

According to the results of this study, surfactant administration through a thin catheter in MIST is a practical and effective treatment method in preterm infants with RDS and could be a good replacement for INSURE as it reduced the NICU hospitalization time and the number of side effects.

\section{Footnotes}

Conflicts of interest: No potential conflict of interest relevant to this article was reported. 
Acknowledgments: This article was extracted from a dissertation by Dr. Sajad Ghahremani to obtain a doctorate in pediatrics. The authors express their appreciation to NICU staff and the Vicechancellor of Research and Technology of Hamadan University of Medical Sciences.

\section{ORCID:}

Mohammad Kazem Sabzehei (D) https://orcid.org/0000-00015304-3512

Behnaz Basiri @ https://orcid.org/0000-0002-3872-9732

Maryam Shokouhi $\odot$ https://orcid.org/0000-0002-5008-7779

\section{References}

1. Condò V, Cipriani S, Colnaghi M, Bellù R, Zanini R, Bulfoni C, et al. Neonatal respiratory distress syndrome: are risk factors the same in preterm and term infants? J Matern Fetal Neonatal Med 2017;30:1267-72.

2. Rubarth LB, Quinn J. Respiratory development and respiratory distress syndrome. Neonatal Netw 2015;34:231-8.

3. Verder H, Robertson B, Greisen G, Ebbesen F, Albertsen P, Lundstrøm $\mathrm{K}$, et al. Surfactant therapy and nasal continuous positive airway pressure for newborns with respiratory distress syndrome. Danish-Swedish Multicenter Study Group. N Engl J Med 1994;331:1051-5.

4. Kumar P, Denson SE, Mancuso TJ, Committee on F, Newborn SOA, Pain M. Premedication for nonemergency endotracheal intubation in the neonate. Pediatrics 2010;125:608-15.

5. Pfister RH, Soll RF. Initial respiratory support of preterm infants: the role of CPAP, the INSURE method, and noninvasive ventilation. Clin Perinatol 2012;39:459-81.

6. Dargaville PA, Aiyappan A, Cornelius A, Williams C, De Paoli AG. Preliminary evaluation of a new technique of minimally invasive surfactant therapy. Arch Dis Child Fetal Neonatal Ed 2011;96:F243-8.

7. Shim GH. Update of minimally invasive surfactant therapy. Korean J Pediatr 2017;60:273-81.

8. Klotz D, Porcaro U, Fleck T, Fuchs H. European perspective on less invasive surfactant administration-a survey. Eur J Pediatr 2017;176:147-54.

9. Jeffreys E, Hunt K, Dassios T, Greenough A. UK survey of less invasive surfactant administration. Arch Dis Child Fetal Neonatal Ed 2019;104: F567.

10. Dargaville PA, Kamlin CO, De Paoli AG, Carlin JB, Orsini F, Soll RF, et al. The OPTIMIST-A trial: evaluation of minimally-invasive surfactant therapy in preterm infants 25-28 weeks gestation. BMC Pediatr 2014;14:213.

11. Aldana-Aguirre JC, Pinto M, Featherstone RM, Kumar M. Less invasive surfactant administration versus intubation for surfactant delivery in preterm infants with respiratory distress syndrome: a systematic review and meta-analysis. Arch Dis Child Fetal Neonatal Ed 2017;102:F17-23.

12. Hartel C, Paul P, Hanke K, Humberg A, Kribs A, Mehler K, et al. Less invasive surfactant administration and complications of preterm birth. Sci Rep 2018;8:8333.

13. Mosayebi Z, Kadivar M, Taheri-Derakhsh N, Nariman S, Mahdi Marashi $S$, Farsi Z, et al. A randomized trial comparing surfactant administration using INSURE technique and the minimally invasive surfactant therapy in preterm infants (28 to 34 weeks of gestation) with respiratory distress syndrome. J Compr Ped 2017;8:e60724.

14. Olivier F, Nadeau S, Bélanger S, Julien AS, Massé E, Ali N, et al. Efficacy of minimally invasive surfactant therapy in moderate and late preterm infants: a multicentre randomized control trial. Paediatr Child Health 2017;22:120-4.

15. Dargaville PA, Aiyappan A, De Paoli AG, Kuschel CA, Kamlin CO, Carlin
JB, et al. Minimally-invasive surfactant therapy in preterm infants on continuous positive airway pressure. Arch Dis Child Fetal Neonatal Ed 2013;98:F122-6.

16. de Kort E, Kusters S, Niemarkt H, van Pul C, Reiss I, Simons S, et al. Quality assessment and response to less invasive surfactant administration (LISA) without sedation. Pediatr Res 2020;87:125-30.

17. Al Ethawi Y. Preliminary evaluation of a new technique of minimally invasive surfactant therapy. J Clin Neonatol 2012;1:66-8.

18. Kanmaz HG, Erdeve O, Canpolat FE, Mutlu B, Dilmen U. Surfactant administration via thin catheter during spontaneous breathing: randomized controlled trial. Pediatrics 2013;131:e502-9.

19. Kribs A, Roll C, Göpel W, Wieg C, Groneck P, Laux R, et al. Nonintubated surfactant application vs conventional therapy in extremely preterm infants: a randomized clinical trial. JAMA Pediatr 2015;169:723-30.

20. Mirnia K, Heidarzadeh M, Hoseini MB, Sadeghnia A, Akrami F, Balila M, et al. Surfactant administration via thin catheter during spontaneous breathing: randomized controlled trial in Alzahra hospital. Iran J Neonatol 2013;4:5-9.

21. Aguar M, Cernada M, Brugada M, Gimeno A, Gutierrez A, Vento M. Minimally invasive surfactant therapy with a gastric tube is as effective as the intubation, surfactant, and extubation technique in preterm babies. Acta Paediatr 2014;103:e229-33.

22. Niemarkt HJ, Kuypers E, Jellema R, Ophelders D, Hutten M, Nikiforou $\mathrm{M}$, et al. Effects of less-invasive surfactant administration on oxygenation, pulmonary surfactant distribution, and lung compliance in spontaneously breathing preterm lambs. Pediatr Res 2014;76:166-70.

23. De Luca D, Minucci A, Gentile L, Capoluongo ED. Surfactant inadvertent loss using feeding catheters or endotracheal tubes. Am J Perinatol 2014;31: 209-12.

24. Janssen LC, Van Der Spil J, van Kaam AH, Dieleman JP, Andriessen P, Onland W, et al. Minimally invasive surfactant therapy failure: risk factors and outcome. Arch Dis Child Fetal Neonatal Ed 2019;104:F636-42.

25. Tomar RS, Ghuliani R, Yadav D. Effect of surfactant therapy using orogastric tube for tracheal catheterization in preterm newborns with respiratory distress. Indian J Pediatr 2017;84:257-61.

26. Dunn MS, Kaempf J, de Klerk A, de Klerk R, Reilly M, Howard D, et al. Randomized trial comparing 3 approaches to the initial respiratory management of preterm neonates. Pediatrics 2011;128:e1069-76.

27. Bugter IAL, Janssen LCE, Dieleman J, Kramer BW, Andriessen P, Niemarkt HJ. Introduction of less invasive surfactant administration (LISA), impact on diagnostic and therapeutic procedures in early life: a historical cohort study. BMC Pediatrics 2020;20:421.

28. Wang XA, Chen LJ, Chen SM, Su PH, Chen JY. Minimally invasive surfactant therapy versus intubation for surfactant administration in very low birth weight infants with respiratory distress syndrome. Pediatr Neonatol 2020;61:210-5.

29. Klebermass-Schrehof K, Wald M, Schwindt J, Grill A, Prusa AR, Haiden $\mathrm{N}$, et al. Less invasive surfactant administration in extremely preterm in. fants: impact on mortality and morbidity. Neonatology 2013;103:252-8.

30. Gupta BK, Saha AK, Mukherjee S, Saha B. Minimally invasive surfactant therapy versus InSurE in preterm neonates of 28 to 34 weeks with respiratory distress syndrome on non-invasive positive pressure ventilation-a randomized controlled trial. Eur J Pediatr 2020;179:1287-93.

How to cite this article: Sabzehei MK, Basiri B, Shokouhi M, Ghahremani S, Moradi A. Comparison of minimally invasive surfactant therapy with intubation surfactant administration and extubation for treating preterm infants with respiratory distress syndrome: a randomized clinical trial. Clin Exp Pediatr 2022;65:188-93. https://doi.org/10.3345/cep.2021.00297 